\title{
SPHK1 contributes to cisplatin resistance in bladder cancer cells via the NONO/STAT3 axis
}

\author{
ZIJIA QIN $^{1 *}$, HANG TONG $^{1 *}$, TINGHAO LI ${ }^{1}$, HONGHAO CAO $^{2}$, \\ JUNLONG ZHU ${ }^{1}$, SIWEN YIN ${ }^{1}$ and WEIYANG HE ${ }^{1}$ \\ ${ }^{1}$ Department of Urology, The First Affiliated Hospital of Chongqing Medical University, Chongqing 400016; \\ ${ }^{2}$ Department of Urology, Rongchang Traditional Chinese Medicine Hospital, Chongqing 402460, P.R. China
}

Received May 26, 2021; Accepted August 13, 2021

DOI: $10.3892 / \mathrm{ijmm} .2021 .5037$

\begin{abstract}
Sphingosine-1-phosphate (S1P) serves an important role in various physiological and pathophysiological processes, including the regulation of cell apoptosis, proliferation and survival. Sphingosine kinase 1 (SPHK1) is a lipid kinase that phosphorylates sphingosine to generate S1P. S1P has been proven to be positively correlated with chemotherapy resistance in breast cancer, colorectal carcinoma and non-small cell lung cancer. However, whether SPHK1 is involved in the development of cisplatin resistance remains to be elucidated. The present study aimed to identify the association between SPHK1 and chemoresistance in bladder cancer cells and to explore the therapeutic implications in patients with bladder cancer. Bladder cancer cell proliferation and apoptosis were determined using Cell Counting Kit-8 assays and flow cytometry, respectively. Apoptosis-related proteins were detected via western blotting. The results revealed that SPHK1 was positively correlated with cisplatin resistance in bladder cancer cells, exhibiting an antiapoptotic effect that was reflected by the downregulation of apoptosis-related proteins (Bax and cleaved caspase-3) and the upregulation of an antiapoptotic protein (Bcl-2) in SPHK1-overexpression cell lines. Suppression of SPHK1 by small interfering RNA or FTY-720 significantly reversed the antiapoptotic effect. A potential mechanism underlying SPHK1-induced cisplatin resistance and apoptosis inhibition may be activation of STAT3 via binding non-POU domain containing octamer binding. In conclusion, the present study suggested that SPHK1 displayed significant antiapoptotic effects in cisplatin-based treatment, thus may serve as a potential novel therapeutic target for the treatment for bladder cancer.
\end{abstract}

Correspondence to: Professor Weiyang He, Department of Urology, The First Affiliated Hospital of Chongqing Medical University, 1 Youyi Road, Yuzhong, Chongqing 400016, P.R. China E-mail: weiyang361@aliyun.com

${ }^{*}$ Contributed equally

Key words: cisplatin resistance, bladder cancer, sphingosine kinase 1, apoptosis, non-POU domain containing octamer binding, STAT3

\section{Introduction}

As one of the most prevalent malignant tumor types worldwide, bladder cancer exhibited the fifth highest incidence rate among new confirmed cases of cancer in men in the USA and the estimated death toll reached 13,050, accounting for $4 \%$ of total cancer-related deaths in 2020 (1). According to the European Association of Urology guidelines, the therapeutic options for bladder cancer include radical surgery, neo-adjuvant therapy and traditional chemotherapy (2). The high drug resistance to traditional chemotherapy is a challenge for the treatment of bladder cancer. Although neo-chemotherapy based on cisplatin was considered promising, $40 \%$ of patients experienced therapeutic failure due to acquired chemoresistance $(3,4)$. Therefore, exploring the mechanism underlying the development of cisplatin resistance in bladder cancer cells is important for the optimization of therapeutic strategies.

Sphingosine kinase 1 (SPHK1), which phosphorylates sphingosine to generate sphingosine-1-phosphate (S1P) (5), has been demonstrated to exert various functions at different stages of cancer progression $(6,7)$. SPHK1 exists in the cytoplasm and is phosphorylated (8) to participate in mediating the sensitivity of cancer cells to their corresponding chemotherapy drugs (9). For instance, SPHK1 overexpression contributes to drug resistant to oxaliplatin in the human colon cancer RKO cell line, whereas SPHK1 downregulation increases drug sensitivity to oxaliplatin in the human colon cancer HCT116 cell line (10). A number of studies have reported that SPHK1 could affect the chemoresistance of colorectal cancer by regulating STAT3 expression, influencing tumorigenesis, proliferation and progression $(10,11)$. However, the effect of SPHK1 in promoting cisplatin resistance in bladder cancer cells is not completely understood.

The present study demonstrated that that SPHK1 inhibited apoptosis and promoted cisplatin resistance by forming a complex with the RNA binding protein non-POU domain containing octamer binding (NONO) in bladder cancer cells. Furthermore, NONO modulated STAT3 activity and displayed a negative association with cisplatin responsiveness. The identification of the SPHK1/NONO/STAT3 axis may provide promising insight into the biological characteristics of bladder cancer cells and aid with the identification of alternative therapeutic strategies. 


\section{Materials and methods}

Statistics acquisition. A total of 411 transcriptome profiling files from 430 samples were extracted from The Cancer Genome Atlas (TCGA; https://portal.gdc.cancer.gov/) Genomic Data Commons. Subsequently, two gene sets of chemotherapy-resistant bladder cancer cells [GSE77883 (12) and GSE58624 (13)] and four gene sets of cisplatin-resistant cancer types [GSE58624/bladder, GSE108214/lung (14), GSE140996/ovarian (15) and GSE77515/breast (16)] were obtained from the Gene Expression Omnibus (GEO; https://www.ncbi.nlm.nih.gov/geo) of National Center for Biotechnology Information.

The identification of differentially expressed genes (DEGs) was performed by GEO2R (https://www.ncbi.nlm. nih.gov/geo/geo2r). $\mathrm{P}<0.05$ and $\mid \log \mathrm{FCl}>1.5$ were set as the cut-off criteria. The Venn diagram reflecting the differentially expressed genes was acquired using bio-Venn software (https://www.biovenn.nl/). The Kaplan-Meier survival curve analysis was performed using Gene Expression Profiling Interactive Analysis (http://gepia.cancer-pku.cn/). The cut-off/threshold value was Quartile: Cutoff-High (75\%); Cutoff-Low (25\%).

Patients and tissue samples. Bladder cancer and adjacent healthy tissue samples were obtained from 10 patients admitted to the First Affiliated Hospital of Chongqing Medical University (Chongqing, China; Table I) between April 2020 and January 2021. The fresh samples were washed with PBS and then stored at $-80^{\circ} \mathrm{C}$ prior to RNA extraction. Written informed consent was obtained from patients. The present study was approved by Ethics Committee of the First Affiliated Hospital of Chongqing Medical University (ethical approval no. 2021086).

Cell lines and chemical reagents. Human bladder cancer cell lines (T24, UMUC-3 and 5637) and normal urothelial cells (SV-HUC-1) were purchased from the American Type Culture Collection. Cells were cultured in RPMI-1640 (Corning, Inc.; for T24 and 5637 cells), DMEM (Gibco; Thermo Fisher Scientific, Inc.; for UMUC-3 cells) or F-12K (for SV-HUC-1 cells) containing 10\% FBS (Gibco; Thermo Fisher Scientific, Inc.) at $37^{\circ} \mathrm{C}$ in a humidified incubator containing $5 \% \mathrm{CO}_{2}$. Cisplatin was purchased from Beijing Solarbio Science \& Technology Co., Ltd. FTY-720 was purchased from GLPBio. T24 cells $(1.0 \mu \mathrm{g} / \mathrm{ml})$ were exposed to increasing concentrations of cisplatin $(0.05,0.1,0.2,0.4,0.6,0.8$ or $1.0 \mu \mathrm{g} / \mathrm{ml})$ for 6 months to generate cisplatin-resistant strains (T24/DDP).

Small interfering RNA (siRNA) and lentivirus transfection. All small interfering RNAs (siRNAs) targeting human SPHK1 (siRNA1, siRNA2, siRNA3) and the scrambled negative control (NC) were designed and synthetized by Shanghai GenePharma Co., Ltd. For siRNA transfection, T24 and UMUC-3 cells were cultured in 6 -well plates $\left(5 \times 10^{3}\right.$ cells/well). At $80 \%$ confluence, the culture media was replaced with $1.5 \mathrm{ml}$ basal medium containing $500 \mathrm{ml}$ Lipofectamine ${ }^{\circledR} 2000$ (Invitrogen; Thermo Fisher Scientific, Inc.) and $0.2 \mathrm{nmol}$ siRNA. The sequences of the siRNAs were as follows: si-SPHK1-1\#, 5'-GCAGGCAUAUGGAGUAUGATTUCA UACUCCAUAUGCCUGCTT-3'; si-SPHK1-2\#, 5'-GCGUCA
UGCAUCUGUUCUATTUAGAACAGAUGCAUGACG CTT-3'; si-SPHK1-3\#, 5'-GAGGCUGAAAUCUCCUUCATT UGAAGGAGAUUUCAGCCUCTT-3'; si-NC, 5'-UUCUCC GAACGUGUCACGUTTA CGUGACACGUUCGGAGA ATT-3.

To create cell lines overexpressing SPHK1 or a control vector, a lentiviral system from Shanghai GenePharma Co., Ltd. was used. Empty vector was used as a negative control. For lentivirus transduction, at $50 \%$ confluence, medium containing lentivirus and polybrominated biphenyls was added to T24 cells at a multiplicity of infection of 50, according to the manufacturer's protocol. Polybrene was used to improve the infection efficiency. The transfection temperature was $37^{\circ} \mathrm{C}$ for $24 \mathrm{~h}$. At $24 \mathrm{~h}$ post-transfection, the supernatant was replaced with RPMI-1640, followed by culture for a further $24 \mathrm{~h}$ at $37^{\circ} \mathrm{C}$. Puromycin $(2 \mathrm{ng} / \mathrm{ml})$ was added to the medium for stable selection of transfected cell lines.

$R N A$ extraction and reverse transcription-quantitative PCR $(R T-q P C R)$. Total RNA was extracted from bladder cancer and adjacent healthy tissue samples, as well as cell lines (at $70 \%$ confluence) using TRIzol $^{\circledR}$ reagent (Thermo Fisher Scientific, Inc.) according to the manufacturer's protocol. Total RNA $(1 \mu \mathrm{g})$ was reverse transcribed into cDNA using the PrimeScript RT reagent kit (Takara Bio, Inc.) according to the manufacturer's instructions. qPCR was performed using SYBR Green assays (Takara Bio, Inc.) and an ABI 7500 Real-Time PCR system (Applied Biosystems; Thermo Fisher Scientific, Inc.; $94^{\circ} \mathrm{C} 2 \mathrm{~min}$, one cycle; $94^{\circ} \mathrm{C} 40 \mathrm{sec}, 50^{\circ} \mathrm{C}$ $40 \mathrm{sec}, 72^{\circ} \mathrm{C} 1 \mathrm{~min}$ for 35 cycles and $72^{\circ} \mathrm{C}$ for $5 \mathrm{~min}$ and one cycle). Relative mRNA expression levels were quantified using the $2^{-\Delta \Delta C \mathrm{C}}$ method (17) and normalized to the internal reference gene GAPDH. The following primers were used for qPCR: SPHK1 forward, 5'-GCGUCAUGCAUCUGUUCU ATT-3' and reverse, 5'-UAGAACAGAUGCAUGACGCTT-3'; GAPDH forward, 5'-GCAGCGAGATCCCTCCAAAAT-3' and reverse, 5'-GGCTGTTGTCATACTTCTCATGG-3'. The experiments were replicated three times.

Cell proliferation assay. Cell proliferation was analyzed by performing Cell Counting Kit-8 (CCK-8) assays. At $48 \mathrm{~h}$ post-siRNA transfection, UMUC- 3 and T2 4 cells were seeded $\left(5 \times 10^{3}\right.$ cells/plate) into 96-well plate. After incubation for $48 \mathrm{~h}$, cells were incubated with CCK- 8 reagent for $1 \mathrm{~h}$ in the dark. The number of viable cells was determined by measuring the absorbance at a wavelength of $450 \mathrm{~nm}$ by a microplate reader (Varioskan LUX; Thermo Fisher Scientific, Inc.).

Flow cytometry. siRNA-transfected UMUC-3 and T24 cells were seeded into 6-well plates and incubated with cisplatin $(0,5$ or $10 \mu \mathrm{g} / \mathrm{ml})$ for $48 \mathrm{~h}$. After washing twice with PBS, cells $\left(\sim 1 \times 10^{6} / \mathrm{ml}\right)$ were resuspended in $500 \mathrm{ml}$ PBS. Cells were transferred to $1.5 \mathrm{ml}$ Eppendorf tubes and stained using the FITC Annexin V Apoptosis Detection kit II (BD Biosciences, cat. no. 556570) and incubated in the dark for $10 \mathrm{~min}$ at room temperature according to the manufacturer's protocol. Subsequently, $10 \mu 1$ propidium iodide (PI, Beyotime Institute of Biotechnology) was added to the stained cells and apoptotic cells were distinguished by a fluorescence-activated cell sorting analyzer (FACS; BD Biosciences). The results were 
Table I. Patient information.

\begin{tabular}{lcllccccc}
\hline ID & Age & Sex & Grade & T stage & N stage & M stage & Start & End \\
\hline 1999981 & 78 & Male & Unknown & Unknown & Unknown & Unknown & 20.06 .10 & 20.06 .16 \\
2023999 & 58 & Male & High & T1 & N1 & M0 & 20.04 .05 & 20.04 .16 \\
1903064 & 63 & Female & High & T4 & N0 & M0 & 21.02 .06 & 21.02 .15 \\
2030137 & 56 & Male & High & T2a & N0 & M0 & 20.09 .16 & 20.09 .29 \\
2002228 & 74 & Male & Low & T2b & N0 & M0 & 20.10 .11 & 20.10 .20 \\
2004550 & 73 & Male & High & T3 & N2 & M0 & 21.01 .15 & 21.01 .24 \\
2006935 & 74 & Male & High & T4 & N2 & M0 & 21.01 .15 & 21.01 .26 \\
2025171 & 65 & Male & High & T1 & N0 & M0 & 20.06 .30 & 20.07 .10 \\
1984663 & 64 & Male & High & T1 & N0 & M0 & 20.08 .31 & 20.09 .08 \\
1990615 & 51 & Male & High & T3b & N0 & M0 & 20.07 .15 & 20.07 .23 \\
\hline
\end{tabular}

analyzed by Cytexpert V2.3 (Beckman Coulter, Inc.) software. The apoptotic rate was calculated by the percentage of early + late apoptotic cells.

Western blotting. Proteins were extracted from cell lines using RIPAlysisbuffer(BeyotimeInstituteofBiotechnology)containing $50 \mathrm{mmol} / \mathrm{l} \mathrm{Tris}-\mathrm{HCl}(\mathrm{pH} 7.4), 150 \mathrm{mmol} / \mathrm{l} \mathrm{NaCl}, 1 \%$ Triton X-100, $1 \mathrm{mmol} / \mathrm{l}$ EDTA (pH 8.0) and $1 \mathrm{mmol} / 1$ phenylmethylsulfonyl fluoride. Total protein concentrations were measured using the BCA quantitative kit (Beyotime Institute of Biotechnology). Proteins $(30 \mu \mathrm{g})$ were separated via $12 \%$ SDS-PAGE and transferred to PVDF membranes. After blocking with 5\% skimmed milk for $2 \mathrm{~h}$ at room temperature, the membranes were incubated overnight at $4^{\circ} \mathrm{C}$ with the following primary antibodies: SPHK1 (cat. no. 10670-1-AP; ProteinTech Group, Inc.; 1:1,000), GAPDH (cat. no. AB0037; Shanghai Abways Biotechnology Co., Ltd.; 1:5,000;), NONO (cat. no. 385171; ZenBio, Inc.; 1:1,000), phosphorylated (p)-STAT3 (cat. no. 380906; ZenBio, Inc.; 1:1,000), Bax (cat. no. 50599-2-Ig; Cell Signaling Technology, Inc.; 1:1,000), Bcl2 (cat. no. 12789-1-AP; Cell Signaling Technology, Inc.; 1:1,000) and cleaved caspase-3 (cat. no. 9661; Cell Signaling Technology, Inc.; 1:1,000). After washing three times with TBS-Tween (0.1\%)-20 (TBST), the membranes were incubated with HRP-conjugated secondary antibodies (Cell Signaling Technology, Inc.) for $2 \mathrm{~h}$ at room temperature. After three washes with TBST, the bands were visualized using an ECL system (Bio-Rad Laboratories, Inc.). Protein expression was semi-quantified using Quantity One software (v4.4.0.36; Bio-Rad Laboratories, Inc.).

Co-Immunoprecipitation (Co-IP). After seeding and culture in a $10-\mathrm{cm}$ culture dish for $48 \mathrm{~h}$, cells were washed with PBS and harvested with a specific IP buffer at $4^{\circ} \mathrm{C}$ for $30 \mathrm{~min}$. Cells were centrifuged at $12,000 \mathrm{x} \mathrm{g}$ and $4^{\circ} \mathrm{C}$ for $15 \mathrm{~min}$ to collect the lysate. Subsequently, $2.5 \mu \mathrm{g}$ SPHK1 and IgG primary antibodies were added to each sample, followed by rotation at $4^{\circ} \mathrm{C}$ overnight with a rolling incubator (cat. no. QB-128; Kylin-Bell Instruments Co., Ltd.). Protein A/G beads were added to the cell lysate and then rotated for $7 \mathrm{~h}$ at $4^{\circ} \mathrm{C}$. The beads were washed three times with IP buffer on a magnetic shelf and then boiled in $2 \mathrm{X}$ SDS loading buffer for $10 \mathrm{~min}$. For mass spectrometry experiments, SPHK1-overexpression T24 cells were harvested and lysed at $4^{\circ} \mathrm{C}$. Subsequently, the IP experiment was performed as aforementioned. Tubes containing beads were sent to Trump Biotechnology Co., Ltd. for mass spectrometry and further analysis.

Statistical analysis. Data were expressed as the mean \pm standard deviation.GraphPad Prism 8 software (GraphPad Software, Inc.) and SPSS 22.0 (IBM Corp.) were used for statistical analyses. For statistical comparisons, a paired t-test was used when comparing matched samples and an unpaired t-test for non-matched samples. Dunnett test was the post hoc test used following two-way ANOVA for multiple comparisons. For the Kaplan-Meier survival curve analysis, log-rank was used to compare the curves. $\mathrm{P}<0.05$ was considered to indicate a statistically significant difference. Figures were produced using Adobe Photoshop CC 2018 (Adobe Systems, Inc.).

\section{Results}

Identifying the target gene SHPK1. The gene sets related to chemoresistance in patients with bladder cancer were demonstrated by the gene sets obtained from the GEO database (Fig. 1A and B). The Venn diagram revealed two cross-linked genes among the 885 upregulated genes in the GSE77883 gene set and 36 upregulated genes in the GSE58624 gene set (Fig. 1C). There were six cross-link genes among the four gene sets of selected cisplatin-resistant cancer types (Fig. 1D). Comprehensive analysis of the results demonstrated that SPHK1 was the only gene contained in both cohorts. Therefore, SPHK1 was selected as the target gene in the present study.

SHPK1 is associated with the prognosis of patients with bladder cancer. A higher expression level of SPHK1 was observed in bladder cancer tissues compared with those in healthy adjacent tissues both in the 19 paired samples $(\mathrm{P}=0.00$; Fig. 2A) and TCGA database of 430 clinical samples $(\mathrm{P}=0.016$; Fig. 2B). Kaplan-Meier curves revealed that patients in the high expression SHPK1 group displayed a notably lower overall survival rate compared with those in the low expression group in GEPIA database (Fig. 2C). Immunohistochemical staining images from the Human Protein Atlas database (https://www. proteinatlas.org/) showed that SPHK1 intensity in bladder 
A

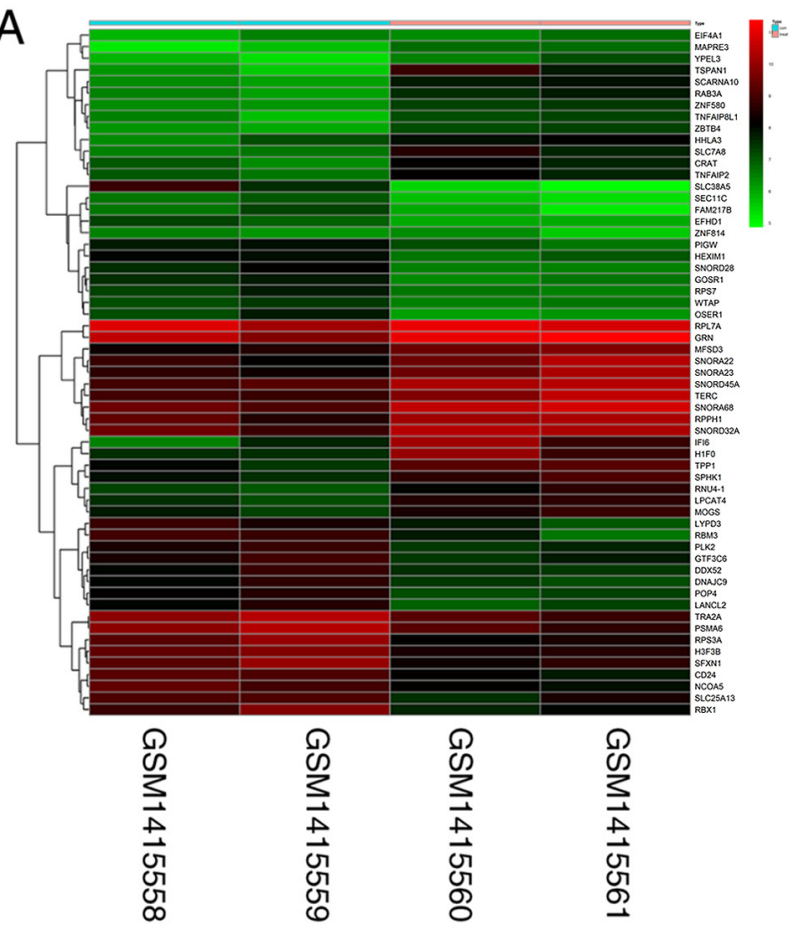

C

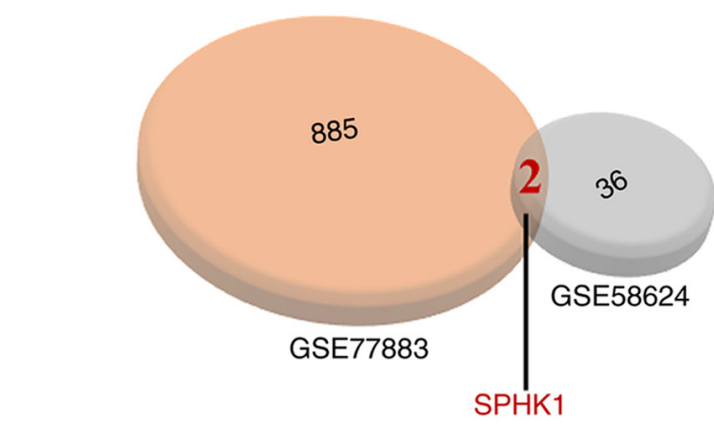

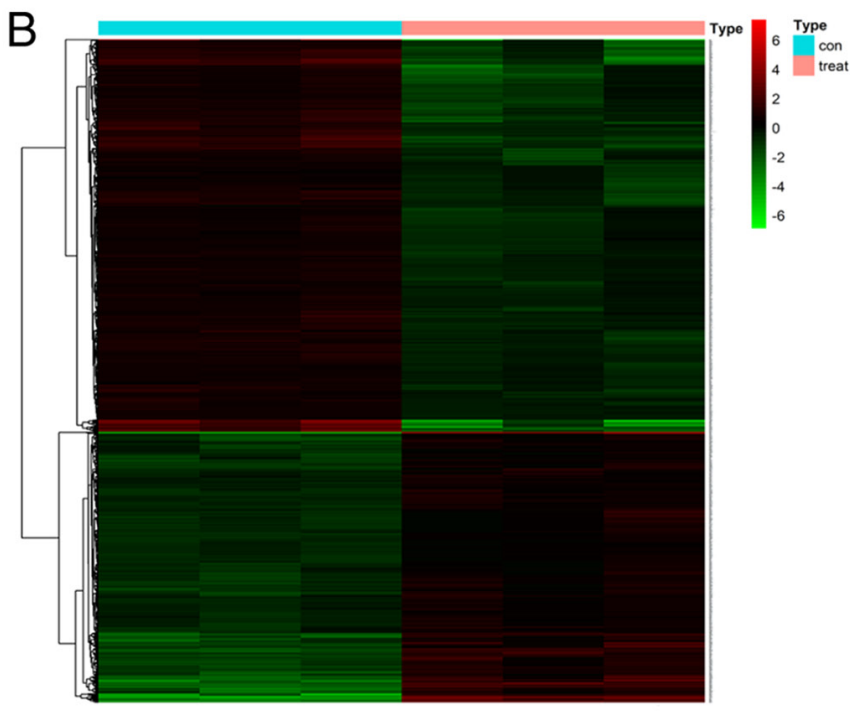

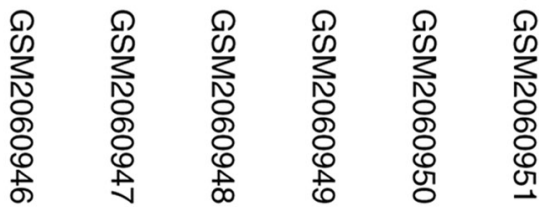

Downregulated DEGs

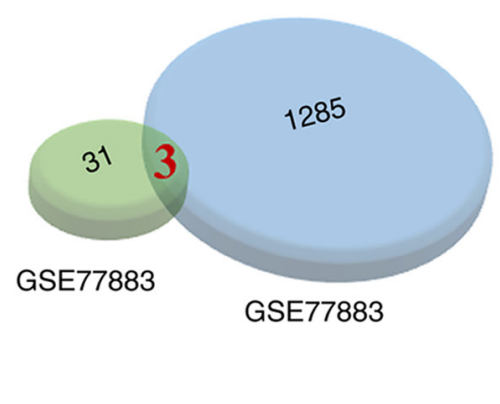

$\mathrm{D}$

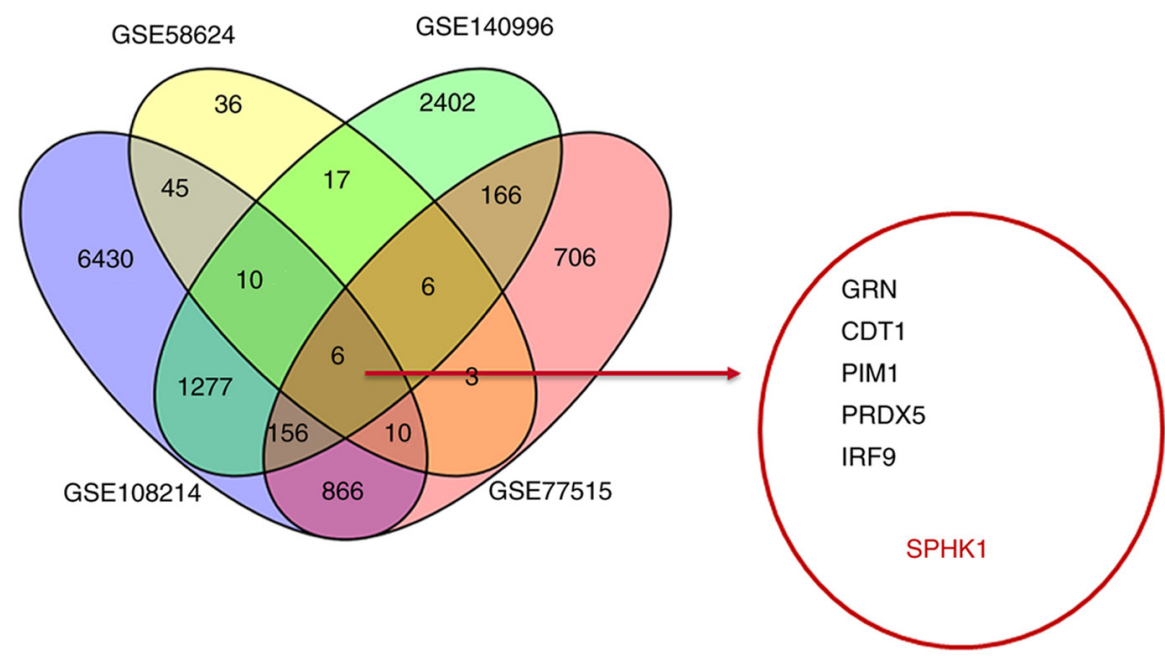

Figure 1. Identifying the target gene sphingosine kinase 1. Gene Expression Omnibus database of the (A) GSE58624 and (B) GSE77883 gene sets of patients with chemoresistant bladder urothelial carcinoma. (C) Venn diagrams of upregulated and downregulated differentially expressed genes. (D) Venn diagram of cisplatin resistant genes in bladder (GSE58624), lung (GSE108214), ovarian (GSE140996) and breast (GSE77515) cancer. SPHK1, sphingosine kinase 1.

cancer tissues was stronger compared with that in adjacent mucosa (Fig. 2D). The RT-qPCR results demonstrated that the higher gene expression of SPHK1 was not only observed in all three bladder cancer cell lines, including T24, 5637 and UMUC-3 (Fig. 2E), but also in the tumor tissues of extracted patients samples (Fig. 2F). Collectively, the results suggested 
A
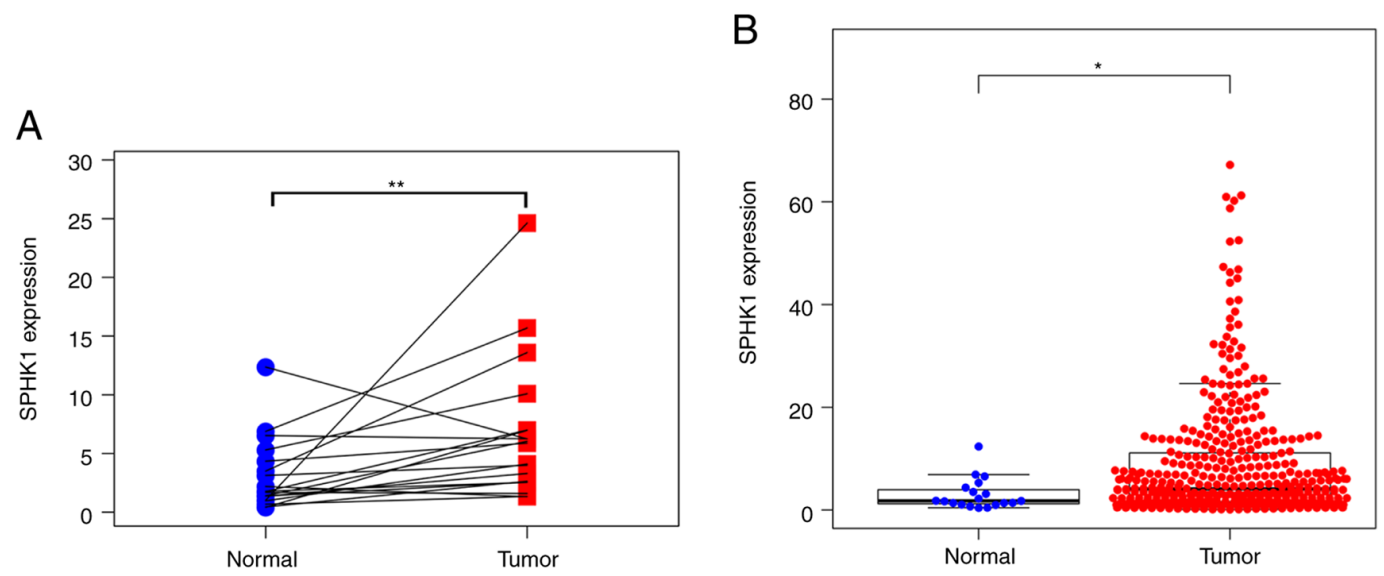

C

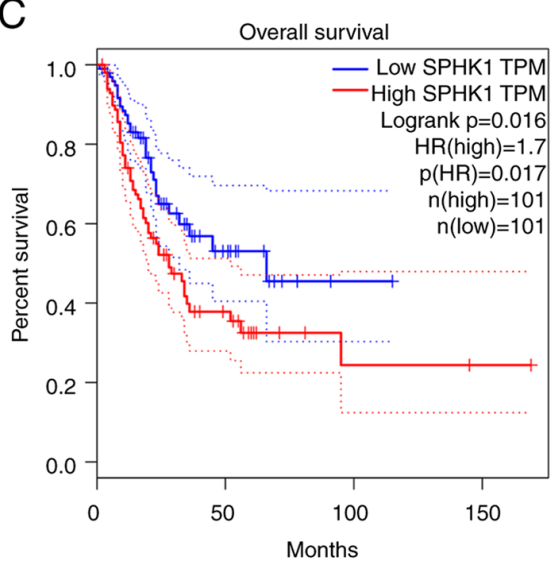

D
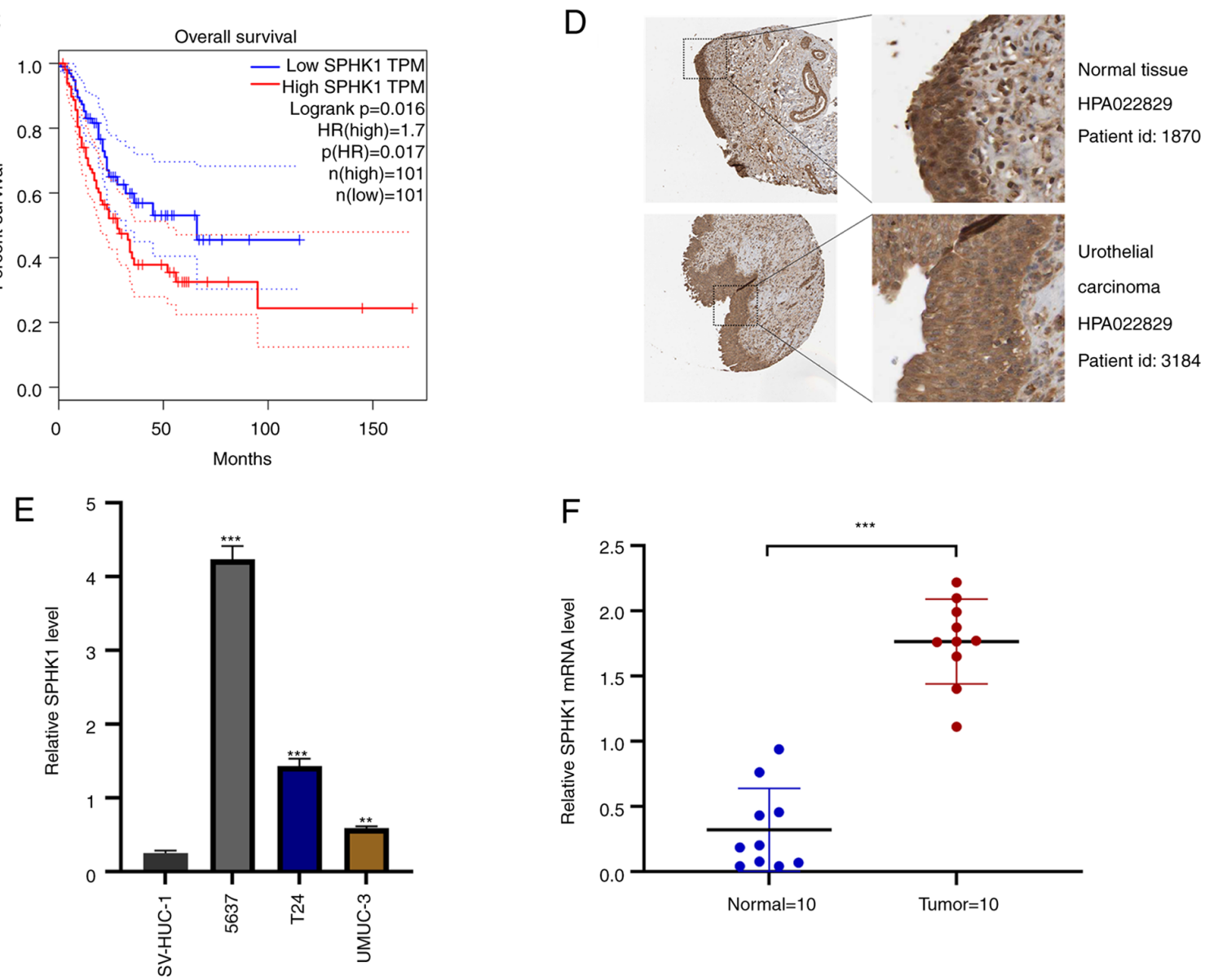

Figure 2. SPHK1 expression in healthy and tumor tissues. (A) SPHK1 expression in paired healthy and tumor tissue samples of 19 patients from TCGA database ( ${ }^{* *} \mathrm{P}<0.01$ Tumor vs. Normal). (B) SPHK1 expression in 430 clinical samples from TCGA database ("P $<0.05$ Tumor vs. Normal). (C) Prognostic analysis of high and low SPHK1 expression groups. (D) Immunohistochemical staining of SPHK1 in healthy urothelial tissues and bladder cancer tissues from the Human Protein Atlas database. (E) SPHK1 expression levels in bladder cancer cell lines and healthy urothelial cells measured by RT-qPCR (*** $<<0.001$ 5637 vs. SV-HUC-1; ${ }^{* * *} \mathrm{P}<0.001$ T24 vs. SV-HUC-1; ${ }^{* *} \mathrm{P}<0.01$ UMUC-3 vs. SV-HUC-1). (F) SPHK1 expression levels in bladder cancer and adjacent healthy tissues from patients with bladder urothelial carcinoma measured by RT-qPCR $\left({ }^{* * *} \mathrm{P}<0.001\right.$ Tumor vs. Normal). SPHK1, sphingosine kinase 1; TCGA, The Cancer Genome Atlas; RT-qPCR, reverse transcription-quantitative PCR.

that SPHK1 was upregulated in bladder cancer and was significantly correlated with the prognosis of patients.

SPHK1 knockdown increases cisplatin sensitivity and promoted the proliferation of bladder cancer cell lines. The role of SPHK1 in the development of cisplatin resistance in bladder cancer cells was investigated. In T24 and UMUC-3 cell lines, SPHK1 knockdown (Fig. 3A and B) led to increased sensitivity to cisplatin treatment compared with the negative control (Fig. 3C and D). At a concentration of $1 \mu \mathrm{g} / \mathrm{ml}$, the two bladder cancer cells were most sensitive to cisplatin treatment $(\mathrm{P}<0.001)$. In addition, the flow cytometry results demonstrated that SPHK1 knockdown displayed a higher rate of apoptosis compared with the negative control (Fig. 3E and F). The results demonstrated that SPHK1 knockdown promoted cell proliferation, increased cisplatin sensitivity and induced apoptosis in bladder cancer cells. 


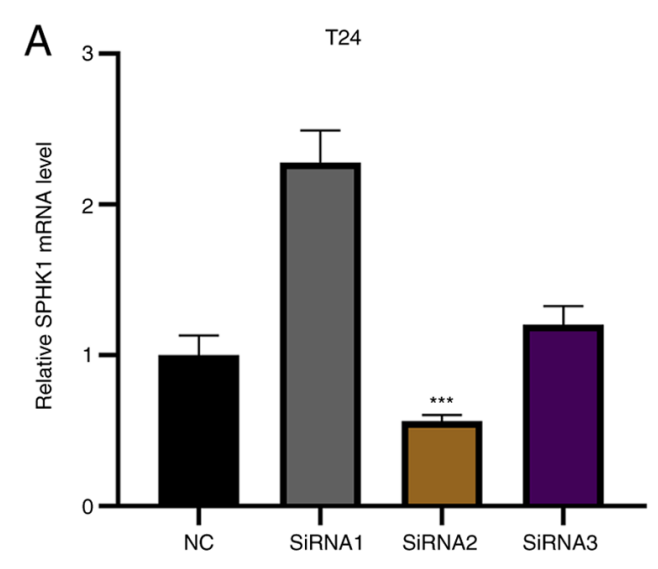

B
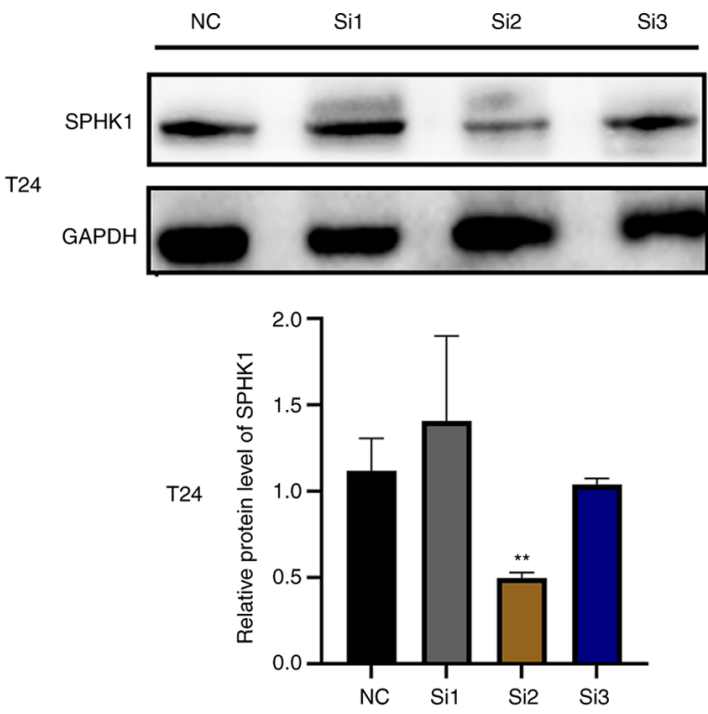

C

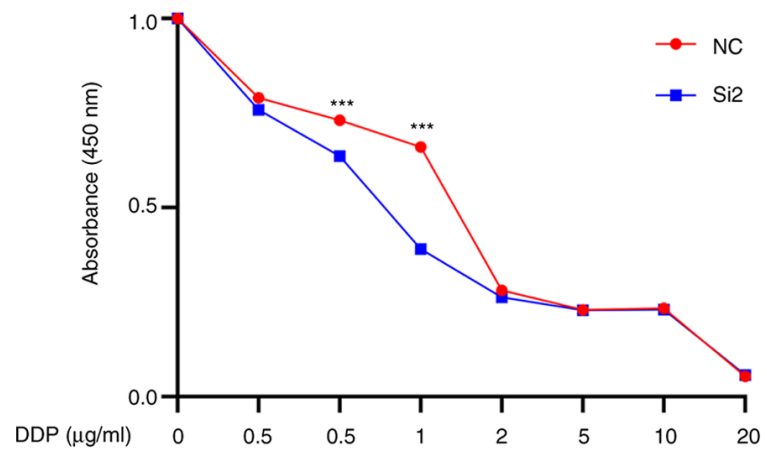

$E$
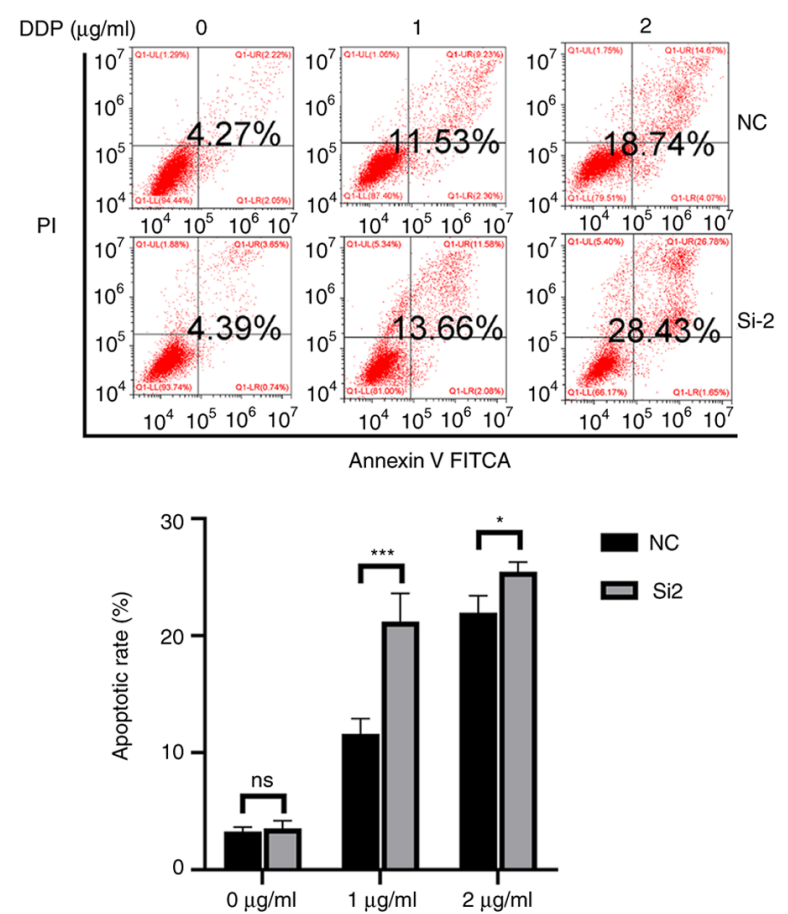

UMUC-3

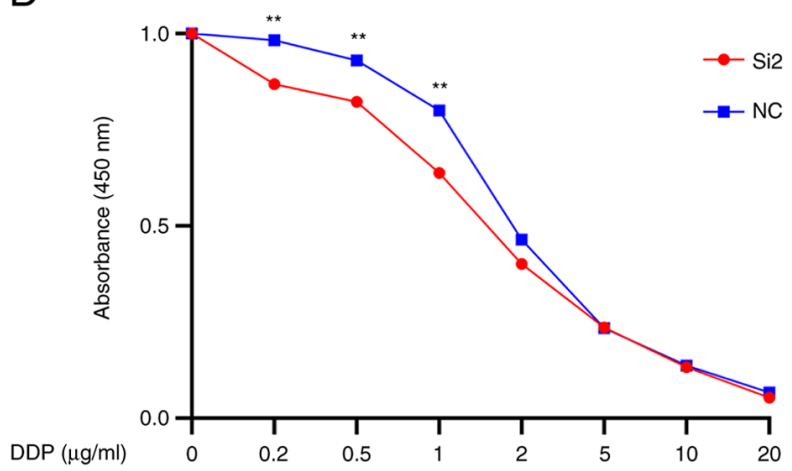

$\mathrm{F}$ UMUC-3
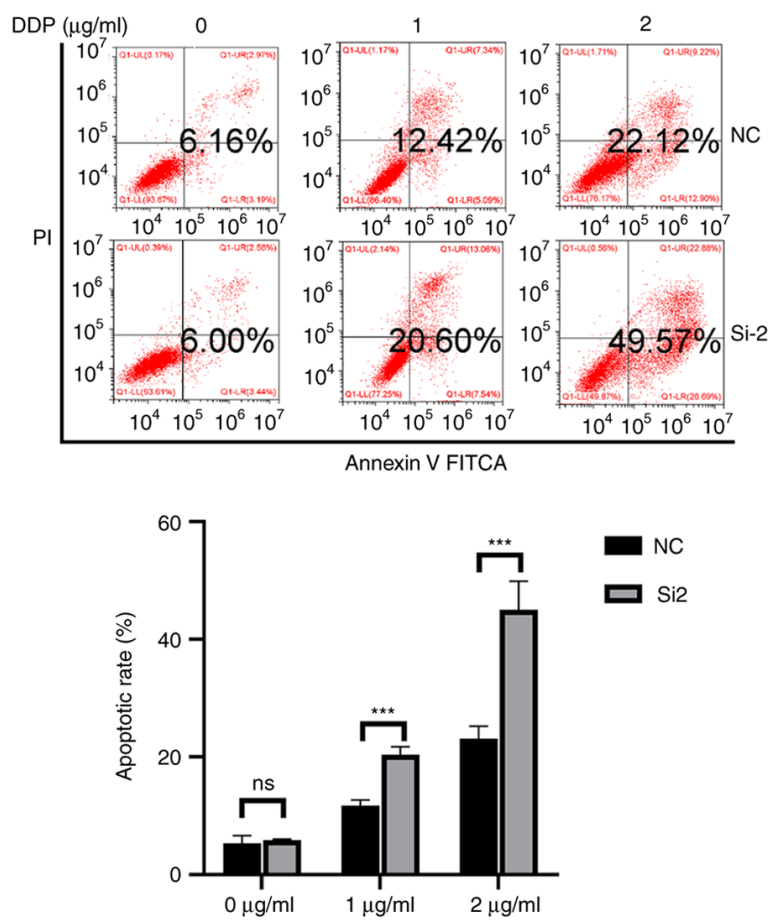

Figure 3. SPHK1 knockdown increases cisplatin sensitivity in bladder cancer cell lines. SPHK1 expression levels in transfected T24 cells were determined by (A) PCR $\left({ }^{* * * *} \mathrm{P}<0.001\right.$ SiRNA2 vs. NC) and (B) western blotting $\left({ }^{* *} \mathrm{P}<0.01 \mathrm{Si} 2\right.$ vs. NC). Cell proliferation was detected in (C) $\mathrm{T} 24-\mathrm{Si}$ vs. NC $\left(0.5 \mu \mathrm{g} / \mathrm{ml}:{ }^{* * * *} \mathrm{P}<0.001\right.$ Si 2 vs. NC, and $1 \mu \mathrm{g} / \mathrm{ml}:{ }^{* * * *} \mathrm{P}<0.001 \mathrm{Si} 2$ vs. NC) and (D) UMUC-3-Si vs. NC $\left(0.2 \mu \mathrm{g} / \mathrm{ml}:{ }^{* * *} \mathrm{P}<0.01 \mathrm{Si} 2 \mathrm{vs}\right.$. NC; $0.5 \mu \mathrm{g} / \mathrm{ml}:{ }^{* * *} \mathrm{P}<0.01 \mathrm{Si} 2 \mathrm{vs}$. NC; $1 \mu \mathrm{g} / \mathrm{ml}:{ }^{* * *} \mathrm{P}<0.01$ $\mathrm{Si} 2$ vs. NC) by performing Cell Counting Kit-8 assays. Apoptosis was analyzed in (E) T24-Si vs. NC (1 $\mu \mathrm{g} / \mathrm{ml}:{ }^{* * *} \mathrm{P}<0.001 \mathrm{Si} 2 \mathrm{vs.} \mathrm{NC;} 2 \mu \mathrm{g} / \mathrm{ml}$ : " $\mathrm{P}<0.05 \mathrm{Si} 2$ vs. NC) and (F) UMUC-3-Si vs. NC (1 $\mu \mathrm{g} / \mathrm{ml}:{ }^{* * *} \mathrm{P}<0.001 \mathrm{Si} 2$ vs. NC; $2 \mu \mathrm{g} / \mathrm{ml}:{ }^{* * *} \mathrm{P}<0.001 \mathrm{Si} 2$ vs. NC) via flow cytometry. SPHK1, sphingosine kinase 1 ; si, small interfering; $\mathrm{NC}$, negative control. 
A

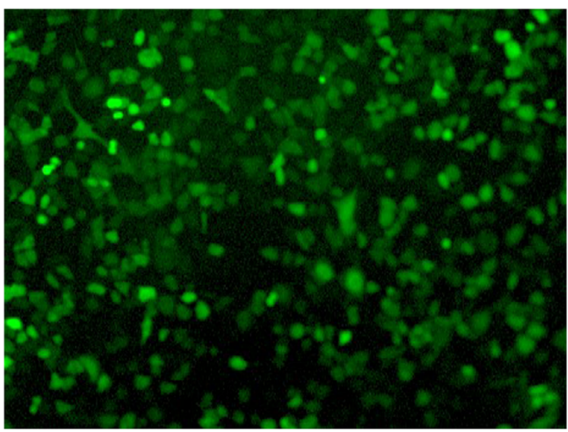

C

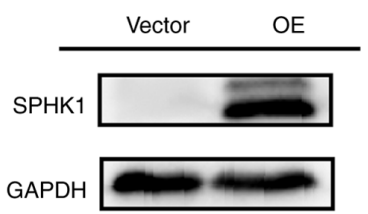

E

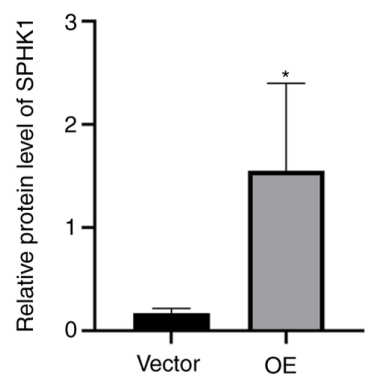

D
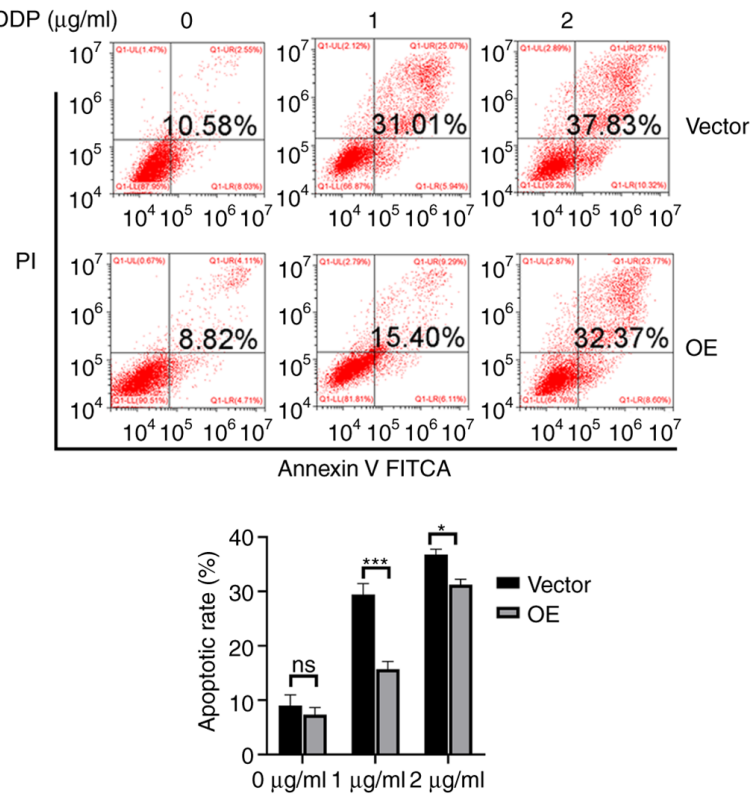

B

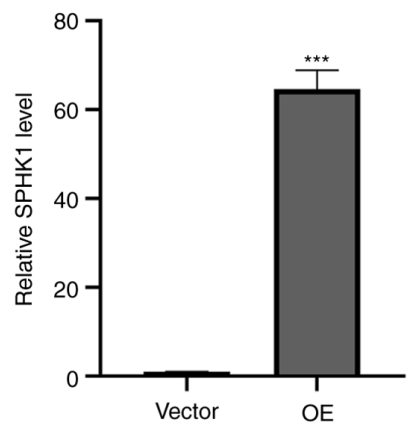

D

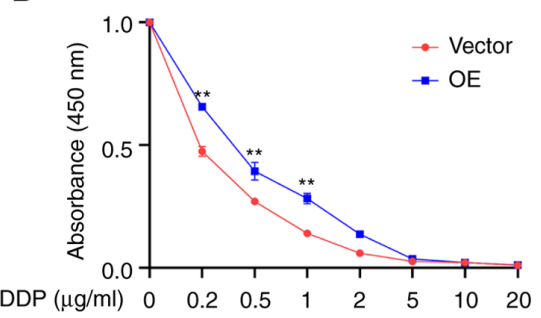

F
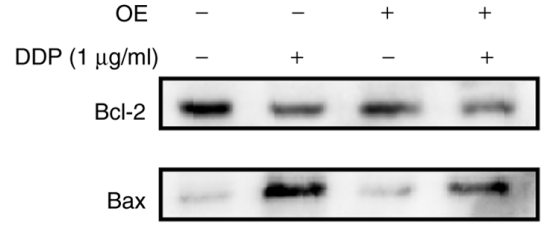

Cleaved caspase-3

GAPDH
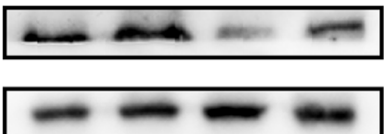

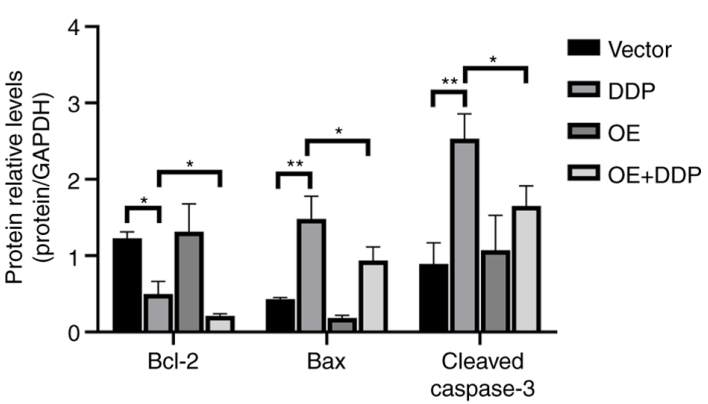

Figure 4. SPHK1 overexpression decreases apoptosis in T24 bladder cancer cells. (A) Construction of SPHK1-overexpression T24 cell lines via lentivirus transduction (magnification, $\mathrm{x} 200$ ). (B) Validation of transfection efficiency via (B) reverse transcription-quantitative PCR $\left({ }^{* * *} \mathrm{P}<0.001 \mathrm{OE}\right.$ vs. Vector) and (C) western blotting ( ${ }^{*} \mathrm{P}<0.05 \mathrm{OE}$ vs. Vector). (D) Cell proliferation was detected in overexpression vs. Vector groups via the Cell Counting Kit- 8 assay $\left(0.2 \mu \mathrm{g} / \mathrm{ml}\right.$ : ${ }^{* *} \mathrm{P}<0.01 \mathrm{OE}$ vs. Vector; $0.5 \mu \mathrm{g} / \mathrm{ml}$ : ${ }^{* *} \mathrm{P}<0.01 \mathrm{OE}$ vs. Vector; $1 \mu \mathrm{g} / \mathrm{ml}$ : ** $\mathrm{P}<0.01 \mathrm{OE}$ vs. Vector). (E) Apoptosis was analyzed via flow cytometry $\left(1 \mu \mathrm{g} / \mathrm{ml}\right.$ : ${ }^{* * *} \mathrm{P}<0.001 \mathrm{OE}$ vs. Vector; $2 \mu \mathrm{g} / \mathrm{ml}$ : " $\mathrm{P}<0.05 \mathrm{OE}$ vs. Vector). (F) Apoptosis-related protein expression levels were detected by western blotting $\left({ }^{*} \mathrm{P}<0.05\right.$ and ${ }^{* *} \mathrm{P}<0.01$ ). SPHK1, sphingosine kinase 1; Vector, negative control; OE, overexpression; DPP, cisplatin.

SPHK1 overexpression decreases apoptosis in T24 bladder cancer cells. First, SPHK1-overexpression cell lines were constructed by lentivirus transfection (Fig. 4A). The RT-qPCR and western blotting results showed that the expression level of SPHK1 was significantly increased after viral transduction (Fig. 4B and C). The CCK-8 assay results displayed that
SPHK1 overexpression significantly promoted cell proliferation (Fig. 4D). Flow cytometry results showed that SPHK1 overexpression also decreased the apoptotic rate (Fig. 4E). The expression of apoptosis-related proteins, including $\mathrm{Bcl}-2$, Bax and cleaved caspase-3, were detected using western blotting. In SPHK1-overexpression cell lines, Bcl-2 was significantly 
A

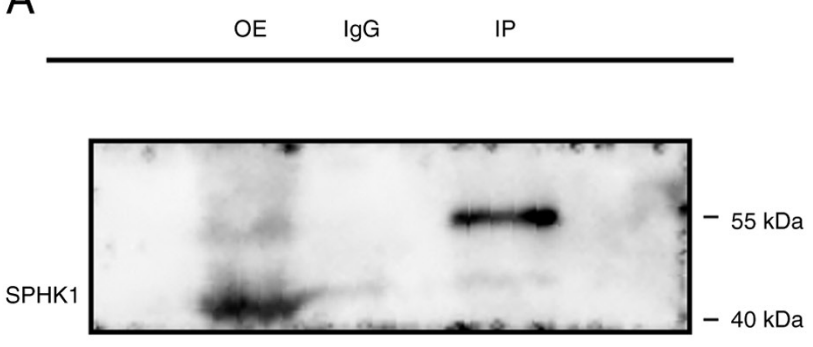

C

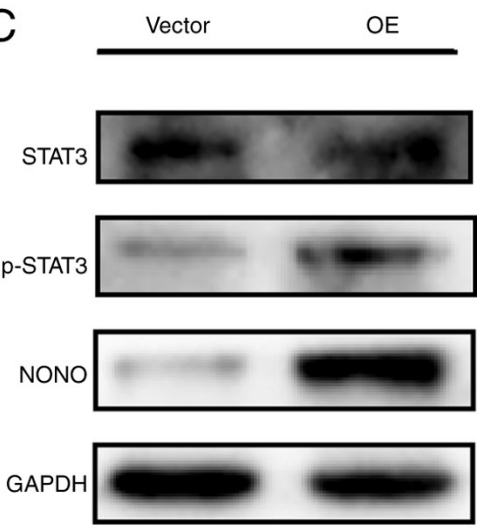

B

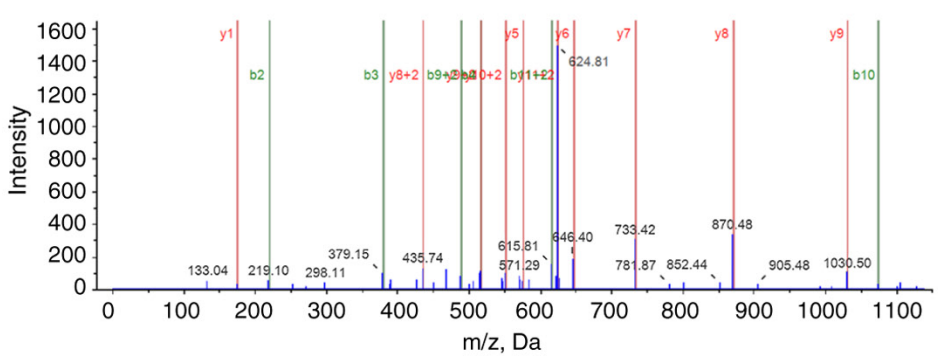

Mass spectrometry: SPHK1

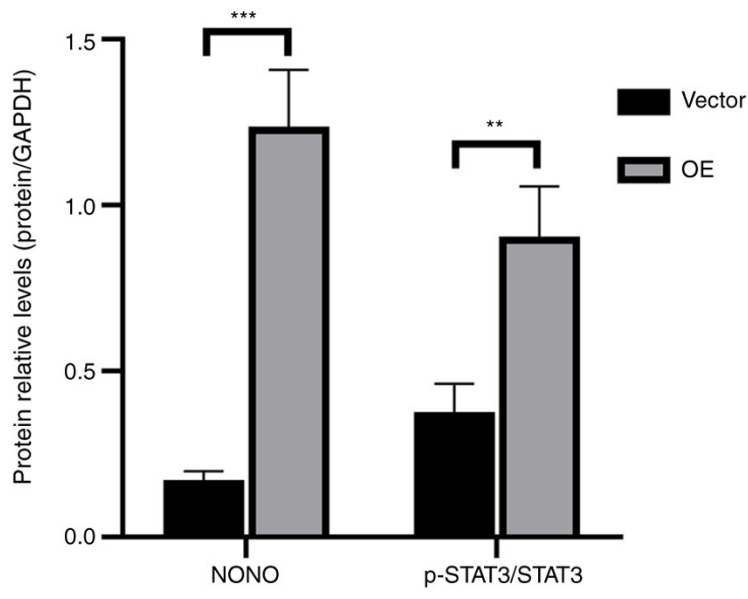

Figure 5. SPHK1 binds to the novel protein NONO and thus affects STAT3 expression in bladder cancer cells. (A) Co-immunoprecipitation confirmed that SPHK1 bound to certain proteins in bladder cancer cells. (B) Mass spectrogram of the target protein NONO. (C) NONO and its downstream target STAT3 were validated via western blotting $\left({ }^{* *} \mathrm{P}<0.01\right.$ and $\left.{ }^{* * *} \mathrm{P}<0.001\right)$. SPHK1, sphingosine kinase 1 ; NONO, non-POU domain containing octamer binding; IP, immunoprecipitation; Vector, negative control; OE, overexpression.

downregulated, whereas Bax and cleaved caspase-3 were upregulated. Compared with normal T24 cells, SPHK1-overexpression T24 cell lines exhibited higher expression levels of Bcl-2 and lower expression levels of Bax and cleaved caspase-3 following treatment with cisplatin (Fig. 4F). The aforementioned results demonstrated that SPHK1 overexpression contributed to cisplatin resistance and decreased apoptosis in bladder cancer cells.

SPHK1 regulates STAT3 expression via binding to NONO. Co-IP was performed to explore the mechanism underlying SPHK1-mediated regulation of apoptosis in bladder cancer cells (Fig. 5A). Based on the mass spectrometry results, a novel protein, NONO, was identified (Fig. 5B). The western blotting results showed that SPHK1-overexpression cell lines displayed higher expression levels of NONO and its downstream signaling molecule p-STAT3 compared with those in normal T24 cells (Fig. 5C).

SPHK1 inhibition reverses antiapoptotic effects in bladder cancer cells. Our previous results demonstrated that SPHK1 is responsible for cisplatin resistance in bladder cancer cells. Numerous studies have demonstrated that FTY-720 is an inhibitor of SPHK1 $(18,19)$ and may induce apoptosis in bladder cancer cells (20). Hence, whether inhibition of SPHK1 by FTY-720 could reverse antiapoptotic effects and increase cisplatin sensitivity in bladder cancer cells was investigated. The western blotting results demonstrated that there was a significant decrease in SPHK1 expression after FTY-720 administration (Fig. 6A). In addition, SPHK1 knockdown led to decreases in NONO and STAT3 expression (Fig. 6B), suggesting that NONO may serve as a downstream regulator of SPHK1. Furthermore, the expression levels of the apoptosis-related proteins Bax and cleaved caspase-3 were increased, whereas Bcl-2 expression levels were decreased after SPHK1 inhibition (Fig. 6C), indicating that SPHK1-induced antiapoptotic effects were dependent on NONO-regulated STAT3 activation.

SPHK1 and corresponding proteins in establishing cisplatin-resistant bladder cancer cell lines. Cisplatin-resistant T24 bladder cancer cells (T24/DDP) were established (Fig. 7A and B). SPHK1, NONO and p-STAT3 were overexpressed in the T24/DDP cell lines (Fig. 7C and D). Following SPHK1 knockdown in T24/DDP cell line, the CCK-8 assay, flow cytometry and western blotting results displayed similar results compared with previous studies (Fig. 7E-H). Therefore, the results demonstrated that SPHK1 promoted cisplatin resistance in bladder cancer cells via binding with NONO and regulating the activation of STAT3.

\section{Discussion}

Tumor progression is regulated by various mechanisms (21-23). The present study demonstrated that SPHK1 overexpression was significantly associated with the development of chemoresistance in bladder cancer cells. Elevated SPHK1 enhanced the 
A
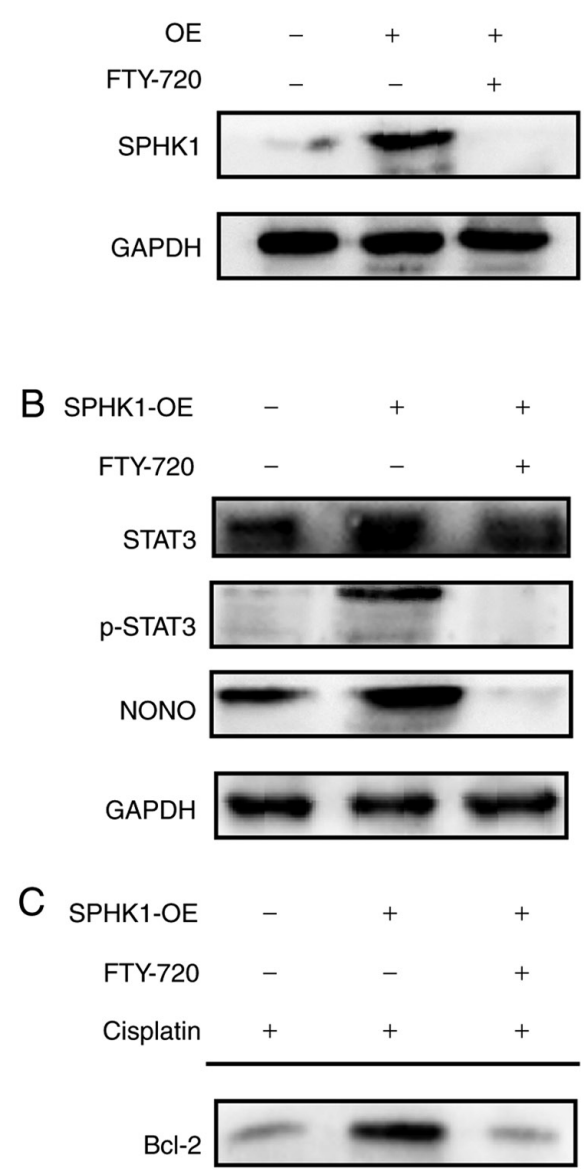

Bax
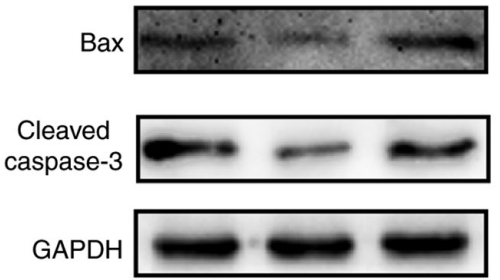
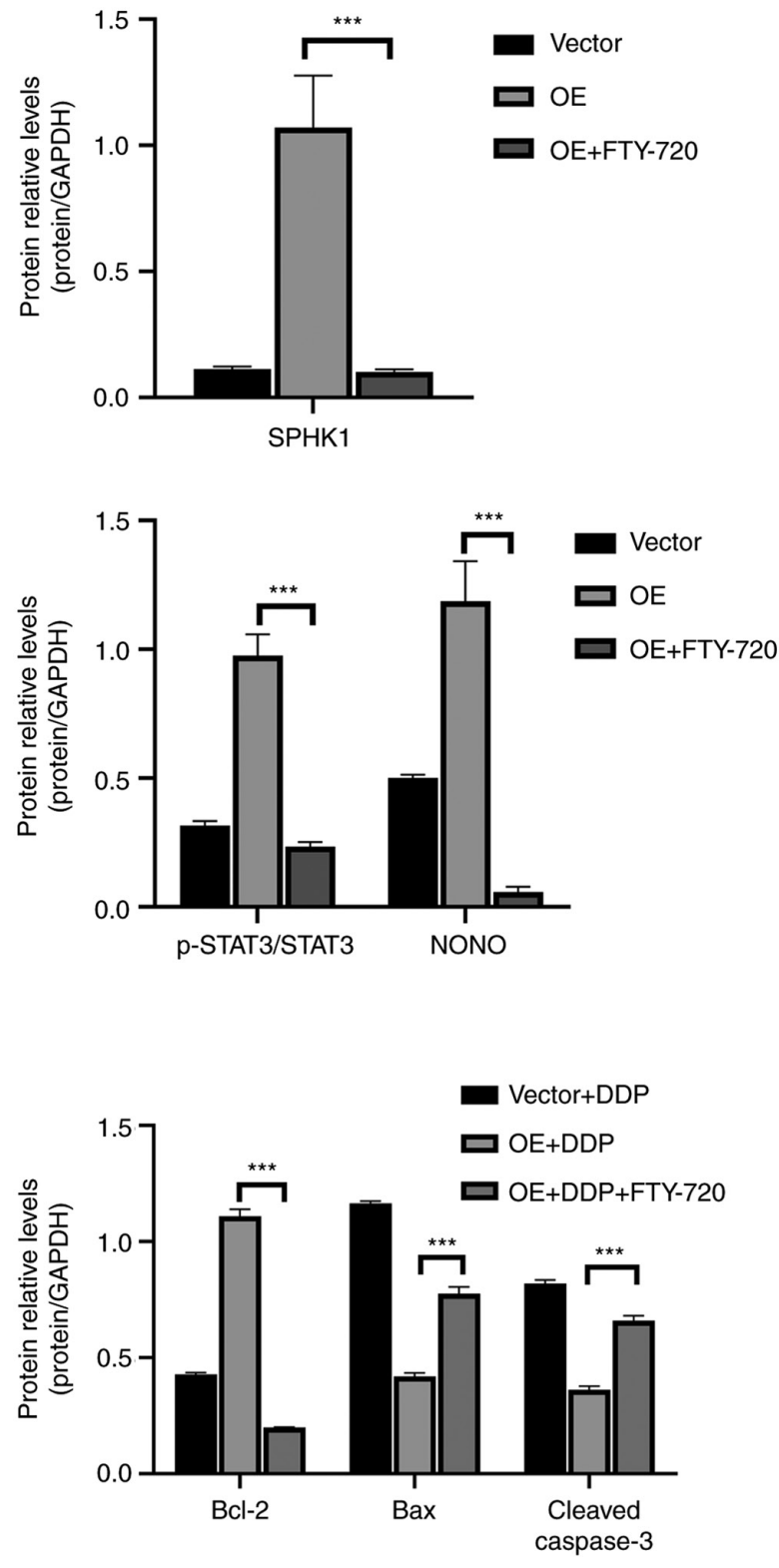

Figure 6. SPHK1 inhibition reverses the antiapoptotic effect in bladder cancer cells. (A) Inhibition efficiency of SPHK1 inhibitor FTY-720 as determined via western blotting $\left({ }^{* * * *} \mathrm{P}<0.001\right)$. (B) Inhibition of SPHK1 decreased the expression of NONO and p-STAT3 $\left({ }^{* * * *} \mathrm{P}<0.001\right)$. (C) Inhibition of SPHK1 decreased apoptosis in bladder cancer cells ( $\left.{ }^{* * *} \mathrm{P}<0.001\right)$. SPHK1, sphingosine kinase 1; NONO, non-POU domain containing octamer binding; p-, phosphorylated; OE, overexpression.

chemoresistance to cisplatin and contributed to poor survival rates in patients with bladder cancer. The chemoresistance to cisplatin was reversed by SPHK1 knockdown via siRNA transfection or FTY-720 treatment.

SPHK1 is reported to influence the biological behaviors of cancer cells, including angiogenesis, cell proliferation and motility, survival, autophagy and apoptosis (9). Mediating apoptosis via suppression of ceramide (24) might be one of the most important oncological implications for overcoming chemoresistance in various cancer cells, leading to an improved prognosis of patients. SPHK1 can induce chemoresistance and inhibit apoptosis in numerous types of cancer, such as acute myeloid leukemia (25), chronic myeloid leukemia (26) and breast cancer (27) and is regarded as a potential sensor to chemotherapy in prostate cancer (28). However, the role of SPHK1 in regulating cisplatin-induced apoptosis in bladder cancer remains to be elucidated. To the best of the authors' knowledge, the present study demonstrated for the first time that SPHK1 inhibition increased the expression of Bax and cleaved caspase-3, but downregulated the expression of the antiapoptotic protein $\mathrm{Bcl}-2$. The $\mathrm{CCK}-8$ assay results demonstrated that SPHK1 was positively associated with bladder cancer cell proliferation. SPHK1-overexpression T24 cells displayed a lower sensitivity to cisplatin treatment. In addition, the present study indicated that inhibition of SPHK1 by FTY-720 enhanced the apoptotic effect of cisplatin treatment in bladder cancer cells.

RNA binding proteins (RBPs) have recently emerged as critical factors that regulate multiple cellular activities, including pre-mRNA splicing, translation and protein sub-cellular localization $(29,30)$. NONO is a novel RBP that is located in the nucleus of numerous mammalian cells and distributed in the sub-nuclear domain and participates in almost every step of gene regulation (31). Studies have found that NONO 


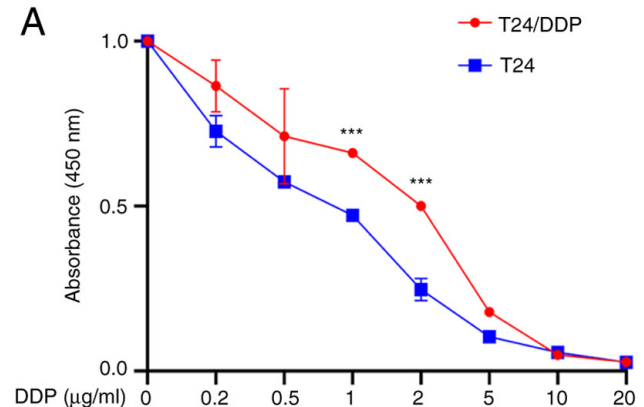

C
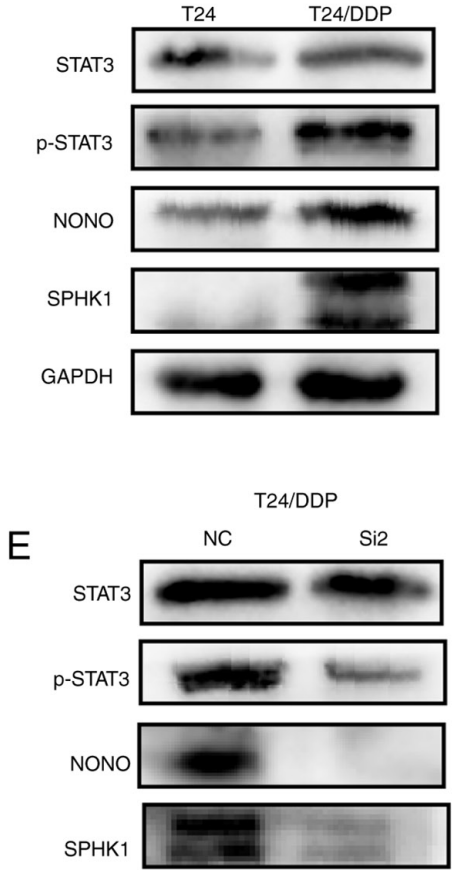

GAPDH

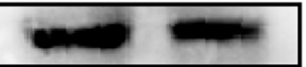

G
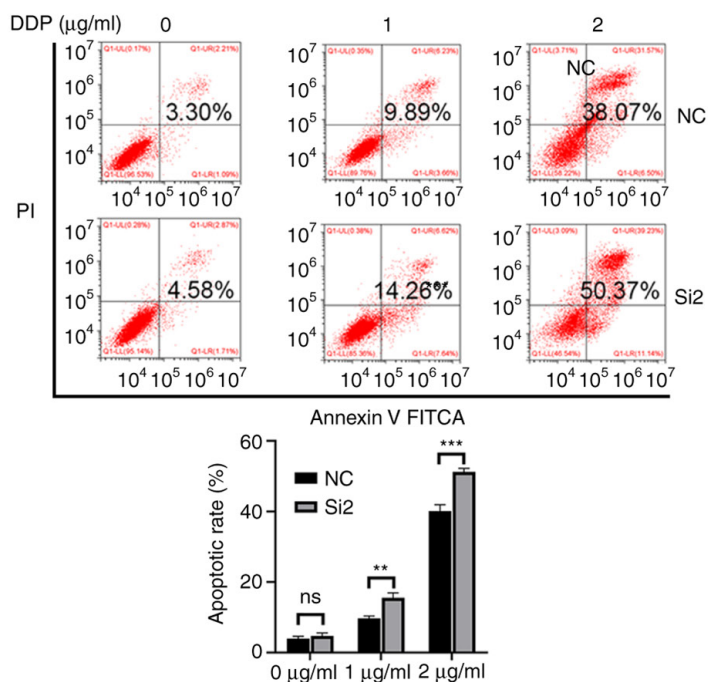

B $\operatorname{DDP}(\mu \mathrm{g} / \mathrm{ml}) \quad 0$
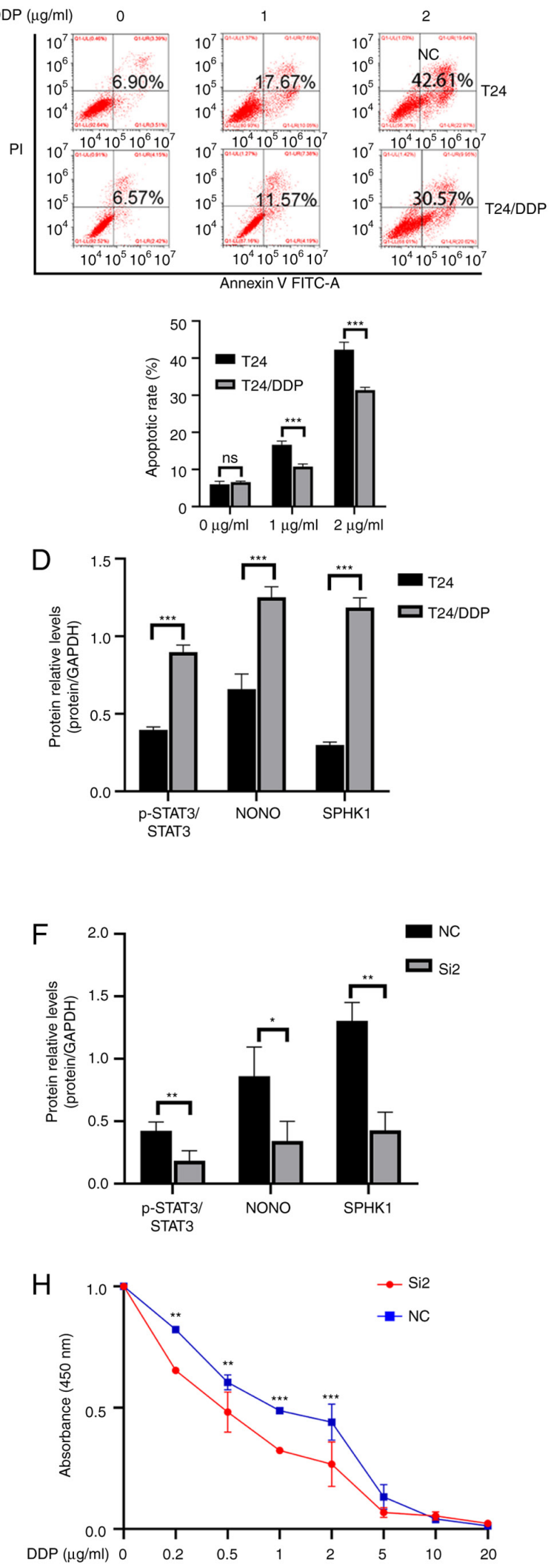

Figure 7. Validation of SPHK1 and its corresponding proteins in the T24/DDP cell line. (A) DPP-resistant T24 bladder cancer cells were established and drug resistance was detected by performing the CCK-8 assay $\left(1 \mu \mathrm{g} / \mathrm{ml}:{ }^{* * *} \mathrm{P}<0.001 \mathrm{~T} 24 / \mathrm{DDP}\right.$ vs. T24; $2 \mu \mathrm{g} / \mathrm{ml}:{ }^{* * * *} \mathrm{P}<0.001$ T24/DDP vs. T24). (B) Apoptosis was analyzed in T24 vs. T24/DDP $\left(1 \mu \mathrm{g} / \mathrm{ml}:{ }^{* * *} \mathrm{P}<0.001 \mathrm{~T} 24 / \mathrm{DDP}\right.$ vs. T24; $2 \mu \mathrm{g} / \mathrm{ml}:{ }^{* * *} \mathrm{P}<0.001 \mathrm{~T} 24 / \mathrm{DDP}$ vs. T24). (C and D) SPHK1, NONO and p-STAT3 were overexpressed in the T24/DDP cell line $\left.{ }^{(* * *} \mathrm{P}<0.001\right)$. Following SPHK1 knockdown in the T24/DDP cell line, the results of (E and F) western blotting, (G) flow cytometry and (H) CCK-8 assay were similar to those reported in previous studies $\left({ }^{*} \mathrm{P}<0.05,{ }^{* *} \mathrm{P}<0.01\right.$ and $\left.{ }^{* * *} \mathrm{P}<0.001\right)$. SPHK1, sphingosine kinase 1 ; DPP, cisplatin; CCK-8, Cell Counting Kit-8; NONO, non-POU domain containing octamer binding; p-, phosphorylated; OE, overexpression. 
also serves an important role in tumorigenesis, including proliferation regulation, DNA damage repair, cell migration and apoptosis (32). For example, silencing NONO can inhibit cell attachment to laminin, poly-1-lysine11 and the surface of culture plates, thus reducing cell migration in melanoma (32) and esophageal cancer (33). Notably, NONO is found to inhibit tumor metastasis in bladder cancer cells (34). Liang et al (35) identified that NONO directly interacted with splicing factor proline/glutamine rich to regulate the splicing of SET domain and mariner transposase fusion gene, thus suppressing the invasion of bladder cancer cells. NONO is also found to promote apoptosis by activating caspase-3 and Bax proteins (36), which is consistent with the results of the present study. In addition, the IP results further indicated that NONO may serve as a pivotal regulator of SPHK1-induced cisplatin resistance and SPHK1 could bind to NONO to inhibit cisplatin-induced apoptosis.

Although the antiapoptotic effect of SPHK1 on bladder cancer cells has been confirmed, the specific mechanism remains unclear. It has been previously reported that SPHK1 phosphorylates sphingosine to generate S1P to activate STAT3 (37). The mechanisms underlying STAT3-mediated induction of cisplatin resistance are complex, including reducing uptake (38-40), cisplatin inactivation $(41,42)$ and most importantly, increasing DNA damage repair (43). It has been reported that cisplatin can form inter- and intrastrand crosslinked DNA adducts in cells and activate the proapoptotic protein P73 (44) and the accumulation of P37 could result in the release of cytochrome $c$ and ultimately lead to cell apoptosis $(45,46)$. DNA mismatch repair (MMR) is a process that corrects mismatched nucleotides by the recognition of inter- and intrastrand DNA adducts and the consequent release of an apoptotic signal. MMR is often impaired in cisplatin-resistant cancer cells (47). MMR deficiency usually results in downregulation of MutS homolog 3 (MSH3), which is associated with cisplatin sensitivity and patient survival (47). Notably, STAT3 activation regulates MSH3 expression in colorectal cancer cells (48). The present study demonstrated that upregulation of p-STAT3 led to increased apoptosis in bladder cancer cells and thus it was suggested that one of the mechanisms underlying SPHK1-induced cisplatin resistance might be regulation of STAT3 expression to activate the downstream signature and inhibit the MMR pathway; however, further investigations are required.

Furthermore, DNA damaged-induced cisplatin resistance can also be reversed by homologous recombination (HR), a non-STAT3-dependent pathway that repairs the double strand breaks (49). Since the HR pathway has been found to serve a role in platinum-based therapy resistance of breast cancer, HR was inhibited by NONO in vivo (50) and the present study demonstrated that SPHK1 could regulate the expression of NONO and it was indicated that SPHK1 might induce cisplatin resistance through the STAT3-dependent pathway, as well as the non-STAT3-dependent HR pathway.

The present study had a number of limitations. First, the lack of in vivo experiments may affect the credibility of the present study. Second, although the present study confirmed the existence of SPHK1/NONO/STAT3 axis, the mechanisms underlying DNA double strands repair are still unclear and require further research.

To the best of the authors' knowledge, the present study demonstrated for the first time that SPHK1 may promote cisplatin resistance and inhibit apoptosis in bladder cancer cells. The antiapoptotic effect of SPHK1 was exerted via binding with the DNA regulating protein NONO. In addition, the combination of SPHK1 and NONO may activate STAT3 to promote the survival of bladder cancer cells.

\section{Acknowledgements}

The authors thank the Laboratory Research Center, The First Affiliated Hospital of Chongqing Medical University (Chongqing, China) for technical support.

\section{Funding}

The present study was supported by the National Natural Science Foundation of China (grant no. 81874092).

\section{Availability of data and materials}

The datasets generated and/or analyzed during the current study are available at TCGA dataset (https://portal.gdc.cancer. gov/) and GEO datasets https://www.ncbi.nlm.nih.gov/geo/ query/acc.cgi?acc=GSE58624; https://www.ncbi.nlm.nih.gov/ geo/query/acc.cgi?acc=GSE108214; https:/www.ncbi.nlm. nih.gov/geo/query/acc.cgi?acc=GSE140996; and https://www. ncbi.nlm.nih.gov/geo/query/acc.cgi?acc=GSE77515.

\section{Authors' contributions}

HT and WH conceived the study. HT and ZQ collected the data. TL, HC, JZ and SY performed the experiments. WH provided project administration and resources. JZ provided software. ZQ drafted the manuscript. HT reviewed and edited the manuscript. HT and ZQ confirm the authenticity of all the raw data. All authors read and approved the final manuscript.

\section{Ethics approval and consent to participate}

The present study was approved by Ethics Committee of the First Affiliated Hospital of Chongqing Medical University (Ethical approval number: 2021086-Ethics Committee of the First Affiliated Hospital of Chongqing Medical University; 3 March 2021.

\section{Patient consent for publication}

Not applicable.

\section{Competing interests}

The authors declare that they have no competing interests.

\section{References}

1. Siegel RL, Miller KD and Jemal A: Cancer statistics, 2020. CA Cancer J Clin 70: 7-30, 2020.

2. Witjes JA, Bruins HM, Cathomas R, Compérat EM, Cowan NC, Gakis G, Hernández V, Linares Espinós E, Lorch A, Neuzillet Y, et al: European association of urology guidelines on muscle-invasive and metastatic bladder cancer: Summary of the 2020 guidelines. Eur Urol 79: 82-104, 2021. 
3. Choi W,Porten S,Kim S, Willis D,PlimackER,Hoffman-Censits J, Roth B, Cheng T, Tran M, Lee IL, et al: Identification of distinct basal and luminal subtypes of muscle-invasive bladder cancer with different sensitivities to frontline chemotherapy. Cancer Cell 25: 152-165, 2014.

4. Shah JB, McConkey DJ and Dinney CP: New strategies in muscle-invasive bladder cancer: On the road to personalized medicine. Clin Cancer Res 17: 2608-2612, 2011.

5. Nguyen AV, Wu YY and Lin EY: STAT3 and sphingosine-1-phosphate in inflammation-associated colorectal cancer. World $J$ Gastroenterol 20: 10279-10287, 2014.

6. Maceyka M, Harikumar KB, Milstien S and Spiegel S: Sphingosine-1-phosphate signaling and its role in disease. Trends Cell Biol 22: 50-60,2012.

7. Pyne S, Edwards J, Ohotski J and Pyne NJ: Sphingosine 1-phosphate receptors and sphingosine kinase 1: Novel biomarkers for clinical prognosis in breast, prostate, and hematological cancers Front Oncol 2: 168, 2012.

8. Pitson SM, Powell JA and Bonder CS: Regulation of sphingosine kinase in hematological malignancies and other cancers Anticancer Agents Med Chem 11: 799-809, 2011.

9. Vadas M, Xia P, McCaughan G and Gamble J: The role of sphingosine kinase 1 in cancer: Oncogene or non-oncogene addiction? Biochim Biophys Acta 1781: 442-447, 2008.

10. Nemoto S, Nakamura M, Osawa Y, Kono S, Itoh Y, Okano Y, Murate T, Hara A, Ueda H, Nozawa Y and Banno Y: Sphingosine kinase isoforms regulate oxaliplatin sensitivity of human colon cancer cells through ceramide accumulation and Akt activation. J Biol Chem 284: 10422-10432, 2009.

11. Shen Z, Feng X, Fang Y, Li Y, Li Z, Zhan Y, Lin M, Li G, Ding Y and Deng H: POTEE drives colorectal cancer development via regulating SPHK1/p65 signaling. Cell Death Dis 10: $863,2019$.

12. Kameyama K, Horie K, Mizutani K, Kato T, Fujita Y, Kawakami K, Kojima T, Miyazaki T, Deguchi T and Ito M: Enzalutamide inhibits proliferation of gemcitabine-resistant bladder cancer cells with increased androgen receptor expression. Int J Oncol 50: 75-84, 2017.

13. Tanaka N, Kosaka T, Miyazaki Y, Mikami S, Niwa N, Otsuka Y, Minamishima YA, Mizuno R, Kikuchi E, Miyajima A, et al: Acquired platinum resistance involves epithelial to mesenchymal transition through ubiquitin ligase FBXO32 dysregulation. JCI Insight 1: e83654, 2016

14. Sarin N, Engel F, Rothweiler F, Cinatl J, Michaelis M, Frötschl R, Fröhlich $\mathrm{H}$ and Kalayda GV: Key players of cisplatin resistance: Towards a systems pharmacology approach. Int J Mol Sci 19 767,2018

15. Wantoch von Rekowski K, König P, Henze S, Schlesinger M, Zawierucha P, Januchowski R and Bendas G: The impact of integrin-mediated matrix adhesion on cisplatin resistance of $\mathrm{W} 1$ ovarian cancer cells. Biomolecules 9: 788, 2019.

16. Chisholm CL, Wang H, Wong AH, Vazquez-Ortiz G, Chen W, $\mathrm{Xu} \mathrm{X}$ and Deng CX: Ammonium tetrathiomolybdate treatment targets the copper transporter ATP7A and enhances sensitivity of breast cancer to cisplatin. Oncotarget 7: 84439-84452, 2016.

17. Livak KJ and Schmittgen TD: Analysis of relative gene expression data using real-time quantitative PCR and the 2(-Delta Delta C(T)) method. Methods 25: 402-408, 2001.

18. Huwiler A and Zangemeister-Wittke U: The sphingosine 1-phosphate receptor modulator fingolimod as a therapeutic agent: Recent findings and new perspectives. Pharmacol Ther 185 34-49, 2018.

19. Lim KG, Tonelli F, Li Z, Lu X, Bittman R, Pyne S and Pyne NJ: FTY720 analogues as sphingosine kinase 1 inhibitors: Enzyme inhibition kinetics, allosterism, proteasomal degradation, and actin rearrangement in MCF-7 breast cancer cells. J Biol Chem 286: 18633-18640, 2011

20. Azuma H, Takahara S, Horie S, Muto S, Otsuki Y and Katsuoka Y: Induction of apoptosis in human bladder cancer cells in vitro and in vivo caused by FTY720 treatment. J Urol 169: 2372-2377, 2003.

21. Sun Z, Niu S, Xu F, Zhao W, Ma R and Chen M: CircAMOTL1 promotes tumorigenesis through miR-526b/SIK2 axis in cervical cancer. Front Cell Dev Biol 8: 568190, 2020.

22. Chen M, Zhuang C, Liu Y, Li J, Dai F, Xia M, Zhan Y, Lin J, Chen Z, He A, et al: Tetracycline-inducible shRNA targeting antisense long non-coding RNA HIF1A-AS2 represses the malignant phenotypes of bladder cancer. Cancer Lett 376 : 155-164, 2016
23. Chen M, Wei X, Shi X, Lu L, Zhang G, Huang Y and Hou J: LncRNA HIF1A-AS2 accelerates malignant phenotypes of renal carcinoma by modulating miR-30a-5p/SOX4 axis as a ceRNA. Cancer Biol Med 18: 587-603, 2021.

24. Cuvillier O, Pirianov G, Kleuser B, Vanek PG, Coso OA Gutkind S and Spiegel S: Suppression of ceramide-mediated programmed cell death by sphingosine-1-phosphate. Nature 381: 800-803, 1996

25. Powell JA, Lewis AC, Zhu W, Toubia J, Pitman MR, Wallington-Beddoe CT, Moretti PA, Iarossi D, Samaraweera SE, Cummings $\mathrm{N}$, et al: Targeting sphingosine kinase 1 induces MCL1-dependent cell death in acute myeloid leukemia. Blood 129: 771-782, 2017.

26. Bonhoure E, Lauret A, Barnes DJ, Martin C, Malavaud B, Kohama T, Melo JV and Cuvillier O: Sphingosine kinase-1 is a downstream regulator of imatinib-induced apoptosis in chronic myeloid leukemia cells. Leukemia 22: 971-979, 2008.

27. Ruckhäberle E, Rody A, Engels K, Gaetje R, von Minckwitz G, Schiffmann S, Grösch S, Geisslinger G, Holtrich U, Karn T and Kaufmann M: Microarray analysis of altered sphingolipid metabolism reveals prognostic significance of sphingosine kinase 1 in breast cancer. Breast Cancer Res Treat 112: 41-52, 2008.

28. Pchejetski D, Golzio M, Bonhoure E, Calvet C, Doumerc N, Garcia V, Mazerolles C, Rischmann P, Teissié J, Malavaud B and Cuvillier O: Sphingosine kinase-1 as a chemotherapy sensor in prostate adenocarcinoma cell and mouse models. Cancer Res 65 : $11667-11675,2005$

29. Gerstberger S, Hafner $M$ and Tuschl T: A census of human RNA-binding proteins. Nat Rev Genet 15: 829-845, 2014.

30. Fox AH and Lamond AI: Paraspeckles. Cold Spring Harb Perspect Biol 2: a000687, 2010.

31. Feng P, Li L, Deng T, Liu Y, Ling N, Qiu S, Zhang L, Peng B, Xiong W, Cao L, et al: NONO and tumorigenesis: More than splicing. J Cell Mol Med 24: 4368-4376, 2020.

32. Schiffner S, Zimara N, Schmid R and Bosserhoff AK: p54nrb is a new regulator of progression of malignant melanoma. Carcinogenesis 32: 1176-1182, 2011.

33. Cheng R, Zhu S, Guo S, Min L, Xing J, Guo Q, Li P and Zhang S: Downregulation of NONO induces apoptosis, suppressing growth and invasion in esophageal squamous cell carcinoma. Oncol Rep 39: 2575-2583, 2018.

34. Xie R, Chen X, Cheng L, Huang M, Zhou Q, Zhang J, Chen Y, Peng S, Chen Z, Dong W, et al: NONO inhibits lymphatic metastasis of bladder cancer via alternative splicing of SETMAR. Mol Ther 29: 291-307, 2021

35. Liang J, Nagahashi M, Kim EY, Harikumar KB, Yamada A, Huang WC, Hait NC, Allegood JC, Price MM, Avni D, et al: Sphingosine-1-phosphate links persistent STAT3 activation, chronic intestinal inflammation, and development of colitis-associated cancer. Cancer Cell 23: 107-120, 2013.

36. Lee H, Deng J, Kujawski M, Yang C, Liu Y, Herrmann A, Kortylewski M, Horne D, Somlo G, Forman S, et al: STAT3-induced S1PR1 expression is crucial for persistent STAT3 activation in tumors. Nat Med 16: 1421-1428, 2010.

37. Bosch-Barrera J, Queralt B and Menendez JA: Targeting STAT3 with silibinin to improve cancer therapeutics. Cancer Treat Rev 58: 61-69, 2017.

38. Zhu H, Luo H, Zhang W, Shen Z, Hu X and Zhu X: Molecular mechanisms of cisplatin resistance in cervical cancer. Drug Des Devel Ther 10: 1885-1895, 2016.

39. Pabla N, Murphy RF, Liu K and Dong Z: The copper transporter Ctr1 contributes to cisplatin uptake by renal tubular cells during cisplatin nephrotoxicity. Am J Physiol Renal Physiol 296: F505-F511, 2009

40. Galluzzi L, Vitale I, Michels J, Brenner C, Szabadkai G Harel-Bellan A, Castedo M and Kroemer G: Systems biology of cisplatin resistance: Past, present and future. Cell Death Dis 5: e1257, 2014

41. Li S, Li C, Jin S, Liu J, Xue X, Eltahan AS, Sun J, Tan J, Dong J and Liang XJ: Overcoming resistance to cisplatin by inhibition of glutathione S-transferases (GSTs) with ethacraplatin micelles in vitro and in vivo. Biomaterials 144: 119-129, 2017.

42. Henrique R, Nunes SP and Jerónimo C: MSH2 expression and resistance to cisplatin in muscle-invasive bladder cancer: A mix of progress and challenges. Eur Urol 75: 251-252, 2019.

43. Tanida S, Mizoshita T, Ozeki K, Tsukamoto H, Kamiya T, Kataoka H, Sakamuro D and Joh T: Mechanisms of cisplatin-induced apoptosis and of cisplatin sensitivity: Potential of BIN1 to Act as a potent predictor of cisplatin sensitivity in gastric cancer treatment. Int J Surg Oncol 2012: 862879, 2012. 
44. Viktorsson K, Ekedahl J, Lindebro MC, Lewensohn R, Zhivotovsky B, Linder S and Shoshan MC: Defective stress kinase and Bak activation in response to ionizing radiation but not cisplatin in a non-small cell lung carcinoma cell line. Exp Cell Res 289: 256-264, 2003.

45. Adams JM: Ways of dying: Multiple pathways to apoptosis. Genes Dev 17: 2481-2495, 2003.

46. Kunkel TA and Erie DA: DNA mismatch repair. Annu Rev Biochem 74: 681-710, 2005.

47. Vaisman A, Varchenko M, Umar A, Kunkel TA, Risinger JI, Barrett JC, Hamilton TC and Chaney SG: The role of hMLH1, hMSH3, and hMSH6 defects in cisplatin and oxaliplatin resistance: Correlation with replicative bypass of platinum-DNA adducts. Cancer Res 58: 3579-3585, 1998.

48. Tseng-Rogenski SS, Hamaya Y, Choi DY and Carethers JM: Interleukin 6 alters localization of hMSH3, leading to DNA mismatch repair defects in colorectal cancer cells. Gastroenterology 148: 579-589, 2015.
49. Rocha C, Silva MM, Quinet A, Cabral-Neto JB and Menck C: DNA repair pathways and cisplatin resistance: An intimate relationship. Clinics (Sao Paulo) 73 (Suppl 1): e478s, 2018.

50. Johnson N, Johnson SF, Yao W, Li YC, Choi YE, Bernhardy AJ, Wang Y, Capelletti M, Sarosiek KA, Moreau LA, et al: Stabilization of mutant BRCA1 protein confers PARP inhibitor and platinum resistance. Proc Natl Acad Sci USA 110: 17041-17046, 2013

This work is licensed under a Creative Commons Attribution-NonCommercial-NoDerivatives 4.0 International (CC BY-NC-ND 4.0) License. 